\title{
ZOA: [:UT

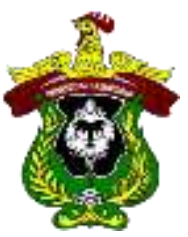

\section{ANALISA CACAT PENGELASAN DENGAN MENGGUNAKAN TEKNIK PENGELASAN DOWN HAND PADA PELAT LAMBUNG (HULL) KAPAL}

\author{
*Sugeng Marsudi \\ Program Diploma Pelayaran Universitas Hang Tuah Surabaya \\ *sugengmarsudi@yahoo.com
}

\begin{abstract}
Abstrak
Pembangunan kapal hampir 2/3 pekerjaan adalah pekerjaan pengelasan. Terdapat beberapa variasi sambungan las sebagai pilihan berdasarkan ketebalan dan kualitas material, metode pengelasan. Hasil pengelasan pada umumnya sangat bergantung pada keterampilan juru las. Kerusakan hasil las baik di permukaan maupun di bagian dalam sulit dideteksi dengan metode pengujian sederhana. Selain itu karena struktur yang dilas merupakan bagian integral dari seluruh badan material las maka retakan yang timbul akan menyebar luas dengan cepat bahkan mungkin bisa menyebabkan kecelakaan yang serius. Secara umum pengelasan pada kapal memiliki persyaratan dari Badan Klasifikasi yang mengawasi dan memberikan kelayakan kekuatan konstruksi kapal. Untuk memenuhi persyaratan tersebut, maka peran juru las dan teknik yang dimiliki sangatlah besar, sehingga kapal mendapatkan mutu las yang baik dan dapat diterima oleh pemilik kapal maupun badan klasifikasi.
\end{abstract}

Kata Kunci: Las, Tekknik Pengelasan, Lambung Kapal.

\begin{abstract}
Abstrct
Shipbuilding nearly 2/3 of the work is welding work. There are several variations of the weld joint as an option based on the thickness and quality of the material, the method of welding. Welding results generally depend heavily on the skill of the welder. Weld damage both on the surface and on the inside is difficult to detect with a simple test method. In addition, because the structure being welded is an integral part of the entire body of the weld material, the cracks that arise will spread quickly and may even cause serious accidents. In general, welding on ships has requirements from the Classification Agency which supervises and provides the feasibility of the ship's construction strength. To meet these requirements, the role of the welder and technique is very large, so that the ship gets good welding quality and can be accepted by the shipowner and the classification agency.
\end{abstract}

Keywords: Welding, Welding Technique, Ship Hull

\section{PENDAhulan}

Dalam pembangunan kapal hampir 2/3 pekerjaan adalah pekerjaan pengelasan, oleh karena itu sepatutnya juru las harus memiliki pengetahuan, pengalaman dan keterampilan tentang teknik pengelasn. Pngerjaan pengelasan terdiri dari tahapan persiapan, pelaksanaan dan finishing. Tahapan persiapan merupakan rangkaian kegiatan mempersiapkan material yang akan di las dan kesiapan alat/perlengkan pengelasan. Tahapan pelaksanan terdiri dari rangkaian kegiatan penyalaan elektroda las dan pengelasn posisi down hand. Terakhir adalah tahapan finishing terdiri dari pembersihan terak las dan penilaian hasil lasn secara visual [1].

Pengelasan pada kapal harus memenuhi persyaratan dari Badan Klasifikasi yang mengawasi dan memberikan kelayakan konstruksi kapal. Selain beroperasi pada fluida yang selalu mendapat gaya hidrostatik, gelombang air dari luar body kapal (hull) juga terdapat beban berat sehingga kapal sebagai sarana pengangkutan perlu mendapatkan perhatian khusus tentang kekuatan dan faktor keselamatannya. Untuk memenuhi persyaratan 
tersebut maka peran juru las sangatlah besar, dan untuk itu teknik - teknik pengelasan pada kapal harus diikuti agar mendapatkan mutu las yang baik dan dapat diterima oleh pemilik kapal maupun badan klasifikasi [2]. Terdapat beberapa variasi sambungan las sebagai pilihan berdasarkan ketebalan dan kualitas material, metode pengelasan dan bentuk struktur [3]. Berdasarkan bentuknya, sambungan las diklasifikasikan antara lain sambungan tumpul, sambungan dengan penguat tunggal, sambungan dengan penguat ganda, sambungan tumpang, sambungan T, sambungan sudut, sambungan tepi, sambungan kampuh melebar dan sambungan bentuk silang. Sambungan-sambungan kampuh las dapat juga diklasifikasikan berdasarkan metode pengelasan, antara lain las tumpul, las sudut, las tepi, las lubang, dan las buildup.

Jika pekerjaan pengelasan dikerjakan dengan tidak benar, bermacam-macam cacat las dapat terjadi, sehingga menghasilkan kualitas sambungan las yang buruk dan tampilan struktur pelat yang dilas tidak memuaskan. Cacat-cacat las dapat terjadi seperti tampilan rigi las buruk, takikan, penumpukan, tidak lurus, terbakar, lubang cacing (keropos), jurang, lubang memanjang, penetrasi kurang, peleburan kurang, terak terperangkap dan retak.

\subsection{Kalsifikasi Las berdasarkan panas listrik}

Terdapat jenis pengelasan dengan menggunakan panas listrik yaitu [4]:

1. SMAW (shelded metal arc welding) adalah las busur nyala listrik terlindung, pengelasan dengan menggunakan busur nyala listrik sebagai sumber panas pencair logam.

2. SAW (submaerged arc welding) las busur terbenam adalah pengelasan dengan busur nyala listrik. Untuk mencegah oksidasi cairan metal dan cairan metal tambahan, dipergunakan butir-butir fluks atau slag, sehingga busur nyala terpendam di dalam butir-butir tesebut.

3. ESW (elektroslog welding) pengelasan busur terhenti. Pengelasan sejenis dengan SAW namun bedanya demikian busur nyala mencairkan fluks, busur terhenti dan peruses pencairan fluks berjalan terus menjadi bahan pengantar arus listrik.

4. ERW (electrical resistanceweld) las tahan listrik. Dengan tahana yang besar, panas yang dihasilkan oleh aliran listrik menjadi sedemikian tingginya sehingga mencairkan logam yang akan dilas.

\subsection{Hasil Pengelasan}

Hasil pengelasan pada umumnya sangat bergantung pada keterampilan juru las. Kerusakan hasil las baik di permukaan maupun di bagian dalam sulit dideteksi dengan metode pengujian sederhana. Selain itu karena struktur yang dilas merupakan bagian integral dari seluruh badan material las maka retakan yang timbul akan menyebar luas dengan cepat bahkan mungkin bisa menyebabkan kecelakaan yang serius. Untuk mencegah kecelakaan tersebut pengujian dan pemeriksaan daerah-daerah las sangatlah penting.

Tujuan dilakukannya pengujian adalah untuk menentukan kualitas produk-produk atau spesimen-spesimen tertentu, sedangkan tujuan pemeriksaan adalah untuk menentukan apakah hasil pengujian itu relatif dapat diterima menurut standar-standar kualitas tertentu atau tidak dengan kata lain tujuan pengujian dan pemeriksaan adalah untuk menjamin kualitas dan memberikan kepercayaan terhadap konstruksi yang dilas. Pengujian/pemeriksaan yang dilakukan sebelum pengelasan meliputi pemeriksaan peralatan las, material pengelasan yang akan digunakan pengujian verifikasi prosedur pengelasan yang harus sesuai dengan prosedur pengelasan yang memadai; dan pengujian kualifikasi juru las sesuai dengan ketrampilan juru las [5].

Pengujian/pemeriksaan yang dilakukan selama proses pengelasanmeliputi pemeriksaan tingkat kekeringan dan kondisi penyimpanan elektrode pengelasan; pemeriksaan las ikat; pemeriksaan kondisi-kondisi pengelasan terpending (arus listrik, tegangan listrik, kecepatan proses pengelasan, urutan proses pengelasan, dsb.); pemeriksaan kondisi-kondisi sebelum dilakukan pemanasan; danpemeriksaan status sumbing-belakang.

Pengujian/pemeriksaan yang dilakukan setelah proses pengelasan meliputi pemeriksaan temperatur pemanasan dan tingkatpendinginan sesudah proses pemanasan dan pelurusan; pemeriksaan visual pada ketelitian ukuran; dan pemeriksaan pada bagian dalam dan permukaan hasil las yang rusak [6].

\section{METODE}

Metode penelitian ini adalah menggunakan metode kajian pustaka, yaitu dengan mengumpilkan berbagai referensi terkait materi yang dibahas serta mempraktekkan langsung di workshop. Objek penelitian berupa pelat baja dengan ukuran $2900 \mathrm{~mm}$ x 20mm x 4mm. Data pengelasan diperoleh dari workshop pengelasan baja 
Universita hang Tuah. Dengan langkah kerja yaitu Pembuatan struktur las meliputi proses pemotongan material sesuai ukuran, melengkungkannya, dan menyambungnya satu sama lain. Elektroda yang digunakan diameter 2,5mm, spesifikasi: AWS A5 IE60103, JIS Z311D3f13, tipe Hight titania (use mild stell) dengan recommended currents sebagai berikut:

Table 3. Recommended currents for electrode

\begin{tabular}{llllll}
\hline Size $(\mathrm{mm})$ & Diaameter & 2,5 & 3.2 & 4,0 & 5,6 \\
\cline { 2 - 6 } & Lenght & 350 & 350 & 400 & 400 \\
Cuweat Rase (Amp) & $60-110$ & $80-140$ & $120-190$ & $160-230$ \\
\hline
\end{tabular}

\section{HASIL DAN PEMBAHASAN}

\subsection{Tahap Persiapan}

Pembuatan specimen dan pemeriksqaan kesiapan alat/perkakas las. Bahan specimen dari besi strip ukran 2900 $\mathrm{mm} \times 20 \mathrm{~mm}$ x $4 \mathrm{~mm}$. Sebelum dilakuakan latihan pengelasan specimen dibersihkan menggunakan amplas dan disikat agar debu yang menempel hilang. Pembuatan specimen dapat dilihat pada gambar berikut
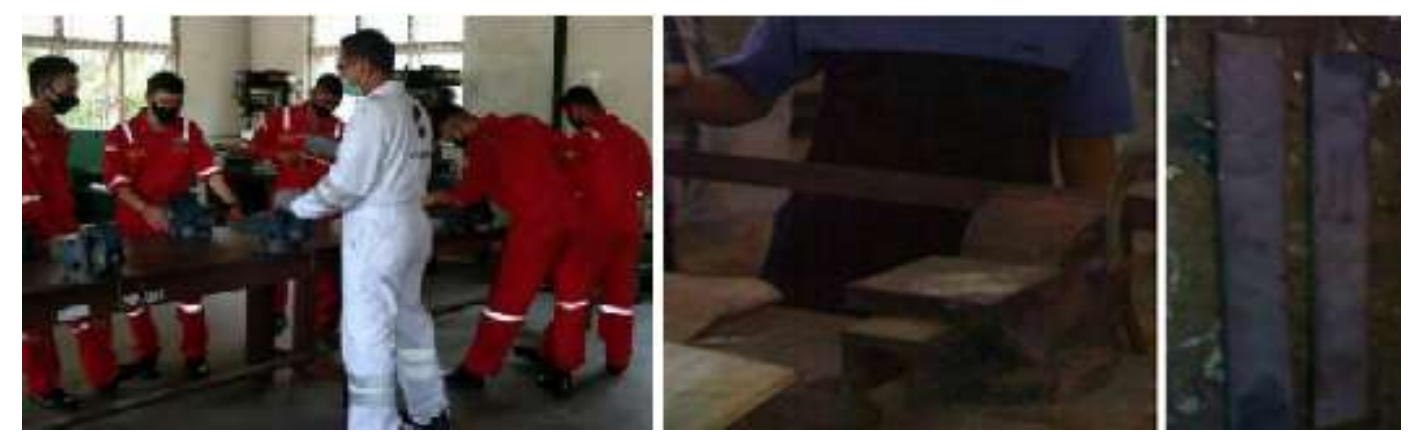

Gambar 1. Pebuatan specimen

Pemeriksaan terhadap momponen alat dan bahan seperti gang las dalam kondisi baik, kabel mesin las tidak ada yang terkelupas, mesin las bisa menyala dan pengatur arus berfungsi baik. Selanjutnya dengan mediakan pelindung muka, kaos tangan, palu, sikat besi dan amplas.

\subsection{Tahap Pelaksanaan}

Kegiatan pengelasan berupa latihan penyalaan dan latihan pengelasan posisi down hand. Sepesimen yang sudah bersih ditetapakan di meja kerja, dengan demikian memungkinkan posisi pengelas dapat melakukan posisi dibawah tangan. Lakukan penyesuaian besar arus, dengan ukuran specimen $2900 \mathrm{~mm}$ x 20mm x 4mm. dan ukuran elektroda diameter 2,5mm. Tahap pelaksanaa pengelasan meliputi :

1. Lakukan latihan penyalaan busur elektroda dengan specimen.

2. Dilanjutkan dengan melakukan latihan mengelas dengan las titik dan gerakan melingkar dalam posisi di bawah tangan.

3. Lakukan las diantara pelat (menyambung pelat). Ulangi beberapa kali sampai mampu melakukan dengan baik.

Arus yang digunakan untuk elektroda dengan diameter 2,5mm adalah 60-110 amper seperti tampilan gambar berikut. 


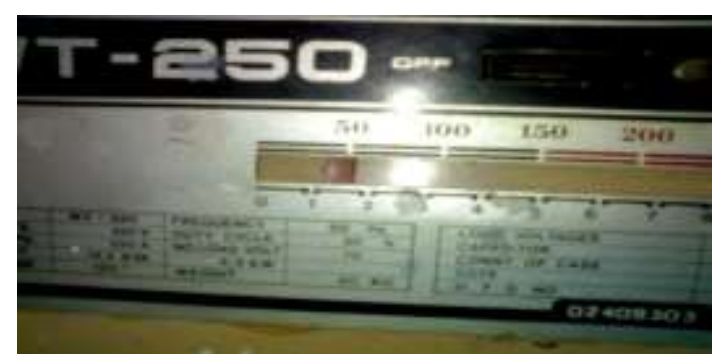

Gambar 2. Besar arus yang digunakan

Jika semuanya telah siap maka dilanjutkan dengan pengelasan specimen tersebut. Pengelasan dimulai dengan pengelasn titik dilanjutkan dengan pengelasan dengan gerak melingkar. Semuanya dilakukan dengan posisi down hand (posisi bawah tangan) seperti ditampilkan pada gambar berikut.

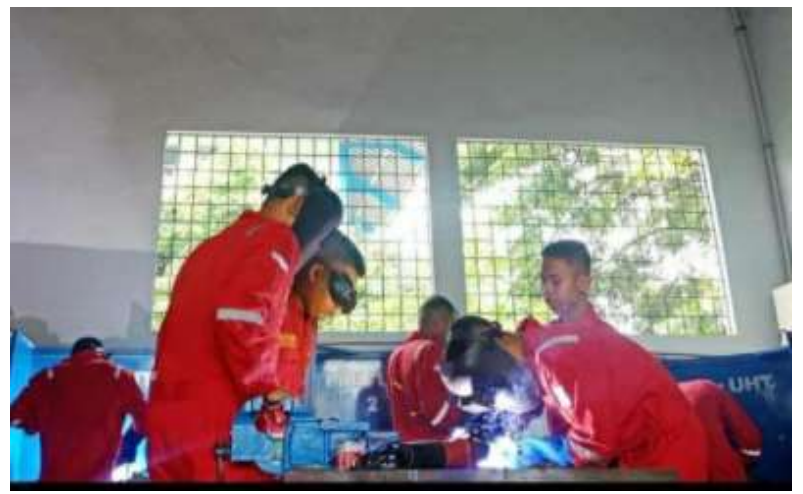

Gambar 3. Pengelasan denga posisi down hand

Selanjutnya yang terakhir Pembersihan terak las dan pemeriksaan hasil lasan secara visual (manual). Bersihkan terak las menggunakan palu dan sikat untuk dapat melihat secara jelas hasil las. Amati hasil las secara visual. Hasil pengelasan dapat dilihat pada gambar berikut.

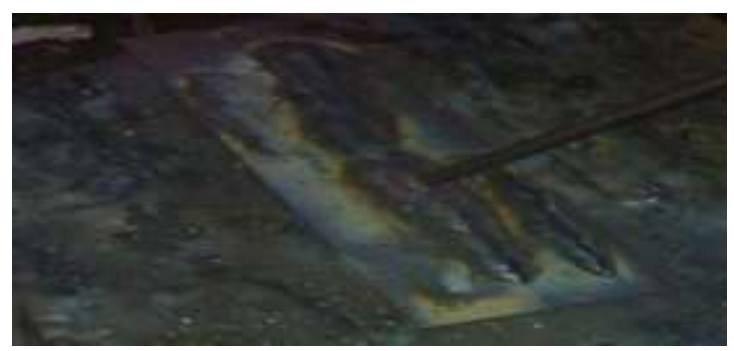

Gambar 4. Hasil pengelasan

\subsection{Evaluasi Hasil Pengelasan}

Kualitas pengelasan sangat tergantung pada ketrampilan juru las dan operator las, oleh karena itu untuk bidang perkapalan badan klasifikasi mensyaratkan kualifikasi tertentu dari juru dan operator las. Dari hasil lasn dapat dilihat mana pengelasan yang sudah benar dan mana pengelasan yang mengalami cacat las. Dapat dilihat pada gambar di bawah ini. 

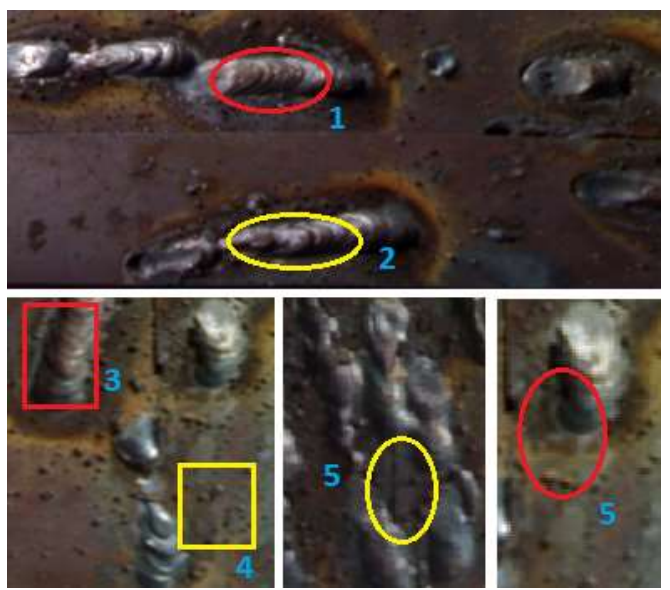

Gamabar 5. Evaluasi hasil pengelasan

Keterangan Gamabr 5.

1. Pengelasan dengan bentuk titik

2. Pengelasn dengan bentuk lingkaran

3. Hasil pengelasan yang sempuna

4. Hasil pengelasan yang putus-putus disebabkan kara pada waktu mengelas elektroda terlalu cepat

5. Hasil pengelasan yang menyebar disebabkan karena elekttroda terlalu jauh dengan specimen sewaktu mengelas

\section{KESIMPULAN}

Pengelasn dibawah tangan (hand down), dimana kemiringan elektroda $80^{\circ}$ dari spesime (besi trip). Mengatur arus sesuai dengan recommended currents for electrode diameter 2,5mm arus $60-110$ amper sangat penting karena hal ini dapat mempengaruhi hasil pengelasan. Setelah elektroda menyala, mempertahankan jarak ujung elektroda dengan ujung pelat (jarak nyala) kira-kira sebesar satu diameter elektroda dan bergerak kearah ujung kampuh yang akan dilas sehingga hasil las akan sempurna.

\section{DAFTAR PUSTAKA}

[1] E. S. Hadi, “Analisa Pengelasan Mild Steel (St.42) Dengan Proses Smaw, Fcaw Dan Saw Ditinjau Dari Segi Kekuatan Dan Nilai Ekonomis," Kapal, vol. 6, no. 2, pp. 107-117, 2012.

[2] S. Wilastari, "Pentingnya Badan Klasifikasi Kapal Dalam Industri Maritim," Din. Bahari, vol. 1, no. 1, pp. 27-30, 2020.

[3] J. T. Perkapalan, “Analisis Variasi Sudut Kampuh Single V-Butt Joint Las Mig pada,” vol. 9, no. 1, pp. $1-10,2021$.

[4] B. A. B. Ii, "PENDEKATAN PEMECAHAN MASALAH A . Grand Livina B . Engine Stand," pp. 633.

[5] A. Bakhori, "Perbaikan Metode Pengelasan Smaw ( Shield Metal Arc Welding ) Pada Industri Kecil Di Kota Medan," Perbaikan Metod. Pengelasan Smaw ( Shield Met. Arc Weld. ) Pada Ind. Kecil Di Kota Medan, vol. 13, no. 1, pp. 14-21, 2017.

[6] Syahnanda Hidayatullah, "Pejuang Mesin Scooter: Pengujian Dan Pemeriksaan Hasil Las," 2010. [Online]. Available: http://santrinekatgmail.blogspot.com/2010/05/pengujian-dan-pemeriksaan-hasillas.html. 